\title{
College Students' Stress Coping Behaviors and Perception of Stress-Effects Holistically
}

\author{
Lauren Rose Dexter ${ }^{1}$, Katie Huff ${ }^{2}$, Mollie Rudecki ${ }^{3} \&$ Sam Abraham $^{4}$ \\ ${ }^{1}$ Medical Surgical Unit, Goshen Health, Goshen, Indiana, USA \\ ${ }^{2}$ American Health Network Hematology/Oncology, Indianapolis, Indiana, USA \\ ${ }^{3}$ Intermediate Care, Memorial Hospital, South Bend, Indiana, USA \\ ${ }^{4}$ Bethel College School of Nursing, Mishawaka. Indiana, USA \\ Correspondence: Sam Abraham, Associate Professor of Nursing, 1001 Bethel Circle, Bethel College School of \\ Nursing, Mishawaka, Indiana, 46545, USA.
}

Received: December 12, 2017

doi:10.20849/ijsn.v3i2.279
Accepted: December 28, 2017

Online Published: January 3, 2018

\begin{abstract}
Objective: The purpose of the current study was to determine college students' stress coping behaviors and perception of stress-effects holistically (emotionally, mentally, and physically).

Participants: The current study was conducted using a convenience sample of 120 students in a Midwestern Christian college with a student population of about 2000. Participants were mostly from the education, nursing, and ministry departments.

Method: A quantitative, cross-sectional, with a descriptive survey design was most suitable for this study.

Results: Students deal with stressors in positive and negative ways. Positive ways included exercise, depending more on faith, and telling themselves that everything will be "Okay." Negative ways included eating more, sleeping less, increased use of the Internet and more procrastination.

Conclusions: College students are aware of constructive ways to cope with stress; however, these techniques are rarely used.
\end{abstract}

Keywords: stress in college students, spiritual life in college students, mental health, holistic, and stress coping behaviors

\section{Introduction}

Lee and Jang (2015) stated, "out of the many factors affecting their satisfaction, the most disturbing one may be that of dealing with stress [something that many people face]" (p. 246). During college life, many students experience changes, including leaving home and friends from high school, higher academic requirements, and starting to find one's personal identity (Lee \& Jang, 2015). As stress affects everyone, it is important for students to know how to cope effectively, especially throughout the college years. The purpose of the current study is to determine college students' stress coping behaviors and perception of stress-effects holistically. The two research questions addressed in the study are: "What are college students' stress coping behaviors?" and, "What are college students' perceptions of stress-effects holistically?"

\section{Background and Significance}

\subsection{Relationships and Stress}

College students, especially freshman, experience many new stressors in their college life. Potential stressors on a college campus are changes in social activities, conflicts with a roommate, new friends, girlfriend or boyfriend, changes in sleep habits, and financial difficulties. Lee and Jang (2015) listed potential stressors on a college campus as change in social activities, conflicts with roommate, new friends, girlfriend or boyfriend, changes in sleep habits, financial difficulties, new responsibilities, change in use of drugs or alcohol, computer problems, increased class load, low class grades, searching for career, car trouble, and messy living conditions.

Hurst, Baranik, and Daniel (2013) indicated the factors that cause college students the most stress were relationships, lack of resources, expectations, and academics. In the relationship category, stressors mainly 
pertained to family, including leaving home, being away from parents and pressure from family members to succeed (Hurst et al., 2013). Anye, Gallien, Bian, and Moulton (2013), discussed the "relationship between spiritual well-being and health-related quality of life" (p. 415). Spending quality time with a higher power can lead a person to feel comforted and spiritual people tend not to engage in as many risky behaviors (Anye et al., 2013).

\subsection{The Internet Use and Stress}

Baghurst and Kelley (2013) stated, "some college students are able to adjust to the overwhelming challenges that arise from this new life experience [transition into college life], whereas others struggle with the escalating stress" (p. 438). Students experience stress and cope differently. Deatherage, Servaty-Seib, and Aksoz (2014) found "Roughly $80 \%$ of college students perceive the Internet to be 'close to' or 'as vital' as air, water, food, and shelter" (p. 40). The Internet usage can cause stress, but also can be used as a coping mechanism to relieve stress. Female college students reported greater levels of stress than male (Deatherage et al., 2014).

In a study of addiction to the Internet usage by college students, Yan, Li, and Sui (2013) found that possible reasons college students became addicted to the Internet included wanting to "manage moods, compensate for social interaction, and escape from reality" (p. 8). Yan et al. (2013) explored stressful life events and the Internet addiction because each individual responds to stress differently. When a person has a high level of psychoticism, aggressiveness, and stressful events are occurring in their life, they are more likely to become obsessed with the Internet; those with low psychoticism who had stressful life events were less likely to become addicted to the Internet (Yan et al., 2013). College students responded differently to stress but there was a high correlation between stressful life events and the Internet addiction.

\subsection{Emotional Eating and Stress}

Wilson, Darling, Fahrenkamp, D'Auria, and Sato (2015) stated that on average 3 out of every 10 college students are classified as overweight or obese. "Increased stress has been associated with a greater preference for energy-dense, high-fat and high-sweet foods" (Wilson et al., p. 164). These findings revealed that coping with stress by eating influenced weight. However, ineffective coping mechanisms, such as emotional eating is not beneficial to maintaining a healthy weight.

\subsection{Spiritual Well-Being and Stress}

In a study of spiritual well-being in college students, Anye et al. (2013) found, "Spirituality has been widely accepted as a dimension or component of health or wellness" (p. 414). The more spiritual the student is, resulted in higher scores in regards to satisfaction of feeling mentally and physically healthy. Students who were not spiritually involved scored lower on the well-being scale (Anye et al., 2013). In regards to mental health, Mahmound, Staten, Hall, and Lennie (2012) found that whenever college students had a support system or a religious affiliation, it helped decrease their levels of stress. Mahmound et al. (2012) established that students who lived together or were involved in a social organization were less anxious, depressed, and stressed than students who did not live together or belong to a social organization.

\subsection{Summary of Review}

In summary, college students are exposed to many stressors. Hurst et al. (2013) found the time limit on exams caused a great deal of stress in the academic category; however, the most common stressor in college was relationships. The Internet, spiritual well-being, and emotional eating were also mentioned. A positive response to stress improves the quality of life and reduces the risk of developing health-related effects of stress. Coping mechanisms vary among students. The freshman and sophomores deal with stress less effectively than juniors and seniors. Peer support and spiritual affiliation helped decrease stress, whereas, irrational eating, procrastination, and the Internet addiction were ineffective means of coping.

\section{Method}

A quantitative, cross-sectional approach with a descriptive survey design was used for this study. A survey instrument was created after a thorough review of the literature. Survey statements were reviewed and critiqued by peers and the faculty to establish face-validity. The survey contained five demographic questions and 20 Likert-type statements.

The Institutional Review Board (IRB) had approved the study before the study was conducted. A convenience sample of 120, in a population of about 2000 college students, participated in the study. The participants were 18 years of age or older, and they signed an informed consent before taking the survey. The surveying took place outside the college library between the hours of 2:00 p.m. to 5:00 p.m. on one day and 4:00 p.m. to 9:00 p.m. on another day during the spring semester of 2016. A table was set up in the lobby of the college library, with the 
permission of the librarian. As students entered or left the library, they were requested to complete a survey. Separate manila envelopes, one for the consents and another for the surveys kept the data separate and confidential. Students who participated were offered a candy bar as an incentive for participating.

\section{Results}

Table 1 contains the descriptive statistics for the participants' demographics. The most common age range was18-23 (95.9\%). The participants included females (54.2\%) and the freshman and sophomores combined accounted for $(69 \%)$ with $80 \%$ living on campus.

Table 1. Demographics

\begin{tabular}{lcc}
\hline Variable & $f$ & $\%$ \\
\hline Gender & 55 & 45.8 \\
Male & 65 & 54.2 \\
$\quad$ Female & 74 & \\
Age range & 41 & 61.7 \\
$18-20$ & 3 & 34.2 \\
$21-23$ & 2 & 2.5 \\
$24-26$ & & 0.07 \\
27 or up & 21 & \\
Class & 25 & 17.5 \\
Senior & 31 & 20.8 \\
Junior & 41 & 25.8 \\
Sophomore & 2 & 43.2 \\
Freshman & & 0.01 \\
Graduate Student & 96 & 80 \\
Housing & 24 & 20 \\
On Campus & & \\
Off Campus &
\end{tabular}

Note. $(N=120)$.

Table 2 contains statements on college students' perception of stress-effects. The statement that participants frequently agreed with was, "Creating a better health in one area of my life spills into other areas of my life" $(\mathrm{M}=3.3, \mathrm{SD}=0.69)$. The participants also tended to agree with the statement "The nature of the relationships I engage in affects my emotional health" $(\mathrm{M}=3.2, \mathrm{SD}=0.87)$. Some participants $(\mathrm{M}=2.0, \mathrm{SD}=1.00)$ indicated suffering from panic attacks as a result of increased stress.

Table 2. College students' perception of stress-effects

\begin{tabular}{lll}
\hline Variable & M & SD \\
\hline Creating better health in one area of my life spills into other areas of my life & 3.3 & 0.69 \\
The nature of the relationships I engage in affects my overall emotional health & 3.2 & 0.87 \\
Wisely dividing my time lessens my anxiety when I am stressed & 3.2 & 0.98 \\
Stress has a negative impact on my physical health & 3.1 & 0.77 \\
It is difficult for me to focus during class when I am stressed & 2.9 & 0.97 \\
The nature of the relationships I engage in affects my overall physical health & 2.9 & 0.92 \\
Stress negatively impacts my social relationships & 2.9 & 0.76 \\
When I am stressed, I have difficulty managing my time & 2.8 & 0.92 \\
I have suffered from panic attacks as a result of increased stress & 2.0 & 1.00 \\
\hline Note. (N=120). Items were rated on a 4-point Likert-type scale using agreement: 1 (Strongly Disagree), 2 \\
(Disagree), 3 (Agree), and 4 (Strongly Agree).
\end{tabular}

Table 3 contains statements on college students' stress coping behaviors. Believing that "everything is going to be okay" when stressed had a mean of $(\mathrm{M}=3.1$; $\mathrm{SD}=0.98)$. Ninety-seven participants answered either "often" or "always" to this statement. Depending more on faith during times of stress was also scored high with $(\mathrm{M}=2.9$; $\mathrm{SD}=0.88)$. 
Table 3. College students' stress coping behaviors

\begin{tabular}{lll}
\hline Variable & M & SD \\
\hline When I am stressed, I choose to believe that everything is going to be "Okay & 3.1 & 0.98 \\
When I am stressed, I depend more on my faith & 2.9 & 0.88 \\
When I am stressed, I sleep less & 2.8 & 0.77 \\
When I am stressed, I use the Internet more & 2.8 & 0.73 \\
When I am stressed, I procrastinate more & 2.6 & 0.78 \\
When I am stressed, I exercise more & 2.6 & 0.71 \\
When I am stressed, I eat more & 2.5 & 0.56 \\
When I am stressed, I cry more & 2.4 & 0.80 \\
When I am stressed, I seek help & 2.3 & 0.85 \\
When I am stressed, I watch more television & 2.2 & 0.78 \\
When I am stressed, I eat at fast food restaurants more & 1.8 & 0.67 \\
\hline
\end{tabular}

Note. $(N=120)$. Items were rated on a 4-point Likert-type scale using frequency: 1 (Never), 2 (Rarely), 3 (Often), and 4 (Always).

\section{Discussion}

The demographic data indicated that transitioning into college life was new [freshmen or sophomores] to most of the students in this study. Many of the students were new to the challenges of stress that college students face and may have skewed the results of this study in relation to managing stress. Based on the literature review, "Some college students are able to adjust to the overwhelming challenges that arise from this new life experience [transition into college life], whereas others struggle with the escalating stress" (Baghurst \& Kelley, 2013, p. 438).

In addition, $80 \%$ reported living on campus and 20\% agreed that they are likely to eat at fast food restaurants when they are stressed. Students who live on campus are required to have a meal plan implying that most of their meals are from on-campus dining areas. Most on-campus students may not find it necessary to go to a fast food restaurant when they can get food that was already paid for in the dining areas.

The item the participants agreed the most in the perception category was, "creating better health in one area of life spills into other areas." The data also indicated that most participants $(76 \%)$ depended on their faith when they became stressed. This data corresponded to Anye et al. (2013) who found the more spiritual the student was, it resulted in higher scores in their satisfaction of feeling mentally and physically healthy. Also, 75.8\% of participants believed that everything is going to be "okay" when they were stressed.

Mahmound et al. (2012) indicated that students who identified with a religion showed signs of less depression and anxiety than students who did not identify with a religion group. There appeared to be a connection between the students' spirituality and reminding themselves that they would be "okay." After analyzing the data about relationships and stress, it became apparent that most of the participants recognized that stress affected their spiritual, mental, and physical development. Significantly high consensus was noted for the statement: The nature of the relationships engaged in affects overall emotional health. In the current study, factors other than spirituality came into play. Only $38.3 \%$ of participants agreed that they sought help in times of stress. A fair number of participants agreed that they cry more when stressed.

A fair number of participants agreed that they eat more when stressed. The data implied that though many students were eating more when stressed, they may not be going out to eat at fast food restaurants. Wilson et al. (2015) reported that "nearly three fourths of college students increase their snack intake when stressed" (p. 164). The current study confirmed the data about increased eating during stress.

Upon analyzing the data about the Internet usage and stress, $62.5 \%$ of participants reported that when stressed they tend use the Internet more often. Deatherage et al. (2014) indicated that the Internet usage can cause stress, but also can be used as a coping mechanism to relieve stress. More than half, $53.3 \%$ of the participants agreed, when they are stressed they tent to procrastinate. It was unclear whether the students were using the Internet as a form of procrastination due to stress or if they were using it as a form of relieving stress.

Positive ways in which the college students managed stress included depending more on their faith and told themselves that they will be "okay." Exercise appeared to be a positive coping mechanism when dealing with stress. Negative ways in which the college students managed their stress included eating more, sleeping less, procrastinating more, and using the Internet more often. Only 38.3\% of students reported seeking help when they 
were stressed indicating that either they did not know where to go for help, or they had knowledge of resources but did not use them.

The data indicated that most college students recognized the effects that stress has on their relationships and holistically (mentally, physically, and spiritually). They also recognized that using time management skills helps in reducing stress. However, when students did not manage their time well, they were more stressed. Most of the participants recognized that stress negatively affected them by making their focus decline during class. Some participants also indicated, experiencing panic attacks during stressful situations. Panic attacks can be a serious condition and individuals who experience them should be medically evaluated.

\section{Limitations}

The first limitation of this study was that the surveying was conducted outside the college library entrance and the participants were mostly traditional students. Many adult and graduate courses at the College are offered online in contrast to traditional classes. Surveying took place for two days at two separate times of the day. Data collection occurred on Wednesday, March 9, 2016, from 2-5 PM and Tuesday, March 15, from 4-9 PM. These times limited the study because it may not have taken into consideration those that studied at the library in the morning. Also, the two surveying days may not have taken into account those who studied on other days of the week. The small sample size of 120 participants in a college student-population of 2000 was another limitation. Future studies with larger sample size and data collection at varying times during the week would be remarkable. While there were limitations, an understanding was gained on how the college students cope with stress.

\section{Implications}

The outcomes of this study may be useful in assessing how students cope, regards to stress and stress management. How individuals cope with stress either negatively or positively impacted their lives. Baghurst and Kelley (2013) stated that "some of the negative physiological consequences of ongoing stress include hypertension, high levels of muscle tension, and lowering of the immune system" (p. 439). Continuing education on stress is seen as a need within the college students.

Stress is inevitable. The majority of participants $(81 \%)$ agreed that stress has a negative impact on their health. Participants have an understanding that stress has an impact on their bodies. Sixty-eight percent of participants agreed that when they are stressed, they have difficulties with time management. The responsibility of being a college student includes successfully managing time, handling the different types of assignments, and adjusting to expectations of college-level work. Students who do not manage their time well are likely to receive poor grades; possibly, even failing out of school. Time management could be a focus of teachings and learning during early college years.

\section{Recommendations}

Stress affected each college student in one way or another. Removing all stressors in college was not possible because of the demands of finishing a large number of courses in four years; however, coping strategies can be used to help manage stress. Based on the current findings, college students do not seek sufficient help when stressed. The majority of participants reported they are less stressed whenever they used time management well; however, $68.3 \%$ of participants agreed or strongly agreed that when stressed, they have difficulty managing their time. Time management strategies need to be emphasized to help lessen stress. Use of the college counseling center should be encouraged. Students may have to meet more often with their advisors. The faculty needs to pay close attention to the performance of the students in class and meet with the stressed individual as the school policy allows. Further research could be conducted probably with a larger sample size to examine how students cope with stress.

\section{Conclusion}

Stress is an unfortunate part of college experience. In this research study, data was gathered to examine how college students cope with stress and how they perceive their stress. Most of the college student participants were aware of the effects of stress holistically (emotionally, mentally, and physically); however, they do not seek adequate help when experiencing stress. Students deal with stressors in positive and negative ways. Students are aware of positive ways to cope with stress; however, these techniques are rarely used. Positive ways include, exercising, seeking help, depending more on their faith, and telling themselves that everything will be "Okay." Negative ways include sleeping less, eating more, and procrastination.

\section{Acknowledgment}

The authors wish to acknowledge Dr. Deborah Gillum, Dean of Nursing, Bethel College, Indiana, for offering 
valuable comments during the early stages of the study. We also like to thank Bethel College administrators for giving us the opportunity to conduct this study.

\section{References}

Anye, E.T., Gallien, T.L., Bian, H., \& Moulton, M. (2013). The relationship between spiritual well-being and health-related quality of life in college students. Journal of American College Health, 61, 414-421. https://doi.org/10.1080/07448481.2013.824454

Baghurst, T., \& Kelley, B. (2013). An examination of stress in college students over the course of a semester. Health Promotion Practice, 15, 438-447. https://doi.org/10.1177/1524839913510316

Deatherage, S., Servaty-Seib, H., \& Aksoz, I. (2014). Stress, coping, and internet use of college students. Journal of American College Health, 62, 40-46. https://doi.org/10.1080/07448481.2013.843536

Hurst, C.S., Baranik, L.E., \& Daniel, F. (2013). College student stressors: a review of the qualitative research. Stress \& Health: Journal of the International Society for the Investigation of Stress, 29, 275-285.

Lee, J., \& Jang, S. (2015). An exploration of stress and satisfaction in college students. Services Marketing Quarterly, 36, 245-260. https://doi.org/10.1080/15332969.2015.1046774

Mahmound, J., Staten, R., Hall, L., \& Lennie, T. (2012). The relationship among young adult college students' depression, anxiety, stress, demographics, life satisfaction, and coping styles. Issues in Mental Health Nursing, 33, 149-156. https://doi.org/10.3109/01612840.2011.632708

Wilson, S., Darling, K., Fahrenkamp, A., D'Auria, A., \& Sato, A. (2015). Predictors of emotional eating during adolescents' transition to college: does body mass index moderate the association between stress and emotional eating? Journal of American College Health, 63, 163-170. https://doi.org/10.1080/07448481.2014.1003374

Yan, W., Li, Y., \& Sui, N. (2013). The relationship between recent stressful life events, personality traits, perceived family functioning and internet addiction among college students. Stress Health, 30, 3-11. https://doi.org/10.1002/smi.2490

\section{Copyrights}

Copyright for this article is retained by the author(s), with first publication rights granted to the journal.

This is an open-access article distributed under the terms and conditions of the Creative Commons Attribution license (http://creativecommons.org/licenses/by/4.0/). 